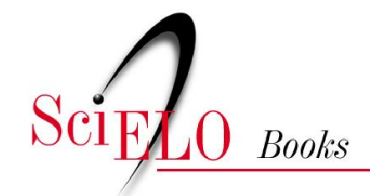

ced

\title{
Carne, consumo ou abolição \\ incompatibilidades nas relações com a carne
}

Marianne Celka

CELKA, M. Carne, consumo ou abolição: incompatibilidades nas relações com a carne. In: PRADO, $\mathrm{SD}$., et al. orgs. Estudos socioculturais em alimentação e saúde: saberes em rede. [online]. Rio de Janeiro: EDUERJ, 2016. Sabor metrópole series, vol. 5, pp. 183-195. ISBN: 978-85-7511-456-8. Available from: doi: 10.7476/9788575114568. Also available in ePUB from:

http://books.scielo.org/id/37nz2/epub/prado-9788575114568.epub

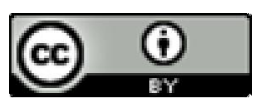

All the contents of this work, except where otherwise noted, is licensed under a Creative Commons Attribution 4.0 International license.

Todo o conteúdo deste trabalho, exceto quando houver ressalva, é publicado sob a licença Creative Commons Atribição 4.0.

Todo el contenido de esta obra, excepto donde se indique lo contrario, está bajo licencia de la licencia Creative Commons Reconocimento 4.0. 


\section{Carne, consumo ou abolição: incompatibilidades nas relações \\ com a carne ${ }^{1,2}$}

Marianne Celka

\section{Introdução}

A carne, nas representações sociais ocidentais, foi considerada, ao longo dos últimos séculos, indicadora de riqueza, sendo seu consumo avaliado como o motor de certa vitalidade individual e social. A partir do que Alvin Toffler nomeou como "industrialidade" (1980), a publicidade desempenhou importante papel no imaginário alimentar, sugerindo uma estética do desejo e reanimando incessantemente a associação entre a carne animal e a sexual (Durand, 1993), propondo reinterpretaçôes do mito de Eros e Thanatos.

Diante dessa institucionalização da carne como elemento positivo, desenvolve-se uma ordem simbólica contraditória, com vistas a estigmatizá-la e condená-la como fonte principal de todos os males sanitários e ambientais concernentes aos países desenvolvidos. A ética vegetariana ressurge, inicialmente, nos anos 1970-1980, na Inglaterra e nos Estados Unidos e, depois, no conjunto dos ditos países desenvolvidos. Essa ética, em seguida, se cristaliza em um modo de vida a priori inédito: o veganismo, espécie de alternativa ao consumismo, tentando renegociar nossa alimentação sob o prisma da valorização da sanidade dos corpos e dos espíritos.

1 Este estudo é uma continuação da tese de doutorado em Sociologia defendida em 2012 na Universidade Paul-Valéry, Montpellier, França.

2 Escrito originalmente em francês, com tradução de Ricardo Ferreira Freitas e Eduardo Bianchi. 
Esse modo de vida se apoia em um conjunto de normas e valores particulares (Celka, 2012), de representaçôes coletivas erigidas em um sistema complexo, ao mesmo tempo ideológico (dogmático) e prático, excluindo todos os produtos de origem animal. Identificando a carne como o marcador flagrante de uma dominação injustificada e injustificável dos homens sobre os animais, espécie de atavismo alimentar, comportamental e moral, o veganismo - que exacerba o vegetarianismo clássico - faz da carne o objeto principal de um ódio e de um desgosto profundos, um tabu, de fato, em torno do qual a comunidade vegan está unida para derrubar a programação social convencional.

Hoje, constatamos certa inclinação difusa, mas, em geral, a favor do veganismo como regime alimentar (muitas vezes, devido ao marketing ou a outros apelos de dietas de emagrecimento) e de um modo de vida "distintivo”. Alguns Olimpos modernos (Morin, 1962) são efígies de uma alimentação alternativa, padrão de uma vida sã e livre, antimaterialista e anticonsumista, que permitem, via seu caráter exemplar, ser o promontório de seus conjuntos de valores. É usando imagens-choque (Barthes, 2010), mas também imagens sedutoras implantadas nas redes eletrônicas, que essa ordem simbólica se capilariza no conjunto do corpo social sem deixar de fustigar o estigma dos "sanguinários" de nossos tempos, em proveito de outros valores contemporâneos evocadores de liberdade e sensibilidade.

Em sua origem, o veganismo como modo de vida ideal, que integra todas as normas e valores relativos ao fenômeno de libertação animal, era contracultural e confrontava a ordem simbólica dominante. Ou seja, propunha-se a ser uma cultura dissidente no interior de uma cultura maior, atacando as fundações legítimas dessa cultura. O veganismo, a seguir, é suavemente destacado dessa marginalidade, em especial pela influência dos grandes organismos de defesa da causa animal (que funcionam como estandartes publicitários com o cortejo de estrelas ou celebridades), mas também - e sobretudo - pelo dinamismo das redes sociais, que permitiram conexão permanente com a militância animal. As múltiplas plataformas de compartilhamento - de imagens, sentidos e emoções - foram o motor para a difusão dessa contracultura, que, pouco a pouco, se tornou uma subcultura. Mais do que isso, hoje em dia o veganismo se infiltra e, ao mesmo tempo, é absorvido pela cultura dominante, tornando-se um modo de consumo entre tantos outros. Isso dito, a carne continua a ser o ponto nodal em torno do qual gravitam as 
representações éticas da alimentação e, nesse sentido, encontra-se no coração de um conflito de valores que problematiza nossa ordem simbólica e social.

\section{A sociedade carnívora}

A construção narrativa moderna do mito das origens do homem fez da depredação, da domesticação animal e da carne os elementos constitutivos da evolução humana, resultando no que somos hoje. De fato, os discursos literários e científicos que valorizam os tempos dos primeiros homens concentram a evolução, ao mesmo tempo física (aumento do tamanho do crânio, por exemplo) e cultural (organização e divisão de tarefas), em torno da caça, dos jogos e do domínio do fogo, e, com isso, da carne cozida. Assim, tanto no romance de J. H. Rosny A guerra do fogo (1909) como nas produções científicas e paracientíficas (romances e vídeos de popularização acadêmica), o futuro humano dos primeiros homens passa, necessariamente, pela utilização e pelo consumo dos outros animais.

A carne, então, na teatralização dos primórdios - podemos recorrer ao illud tempus, de Mircea Eliade (2001) -, é a pedra fundamental do progresso. É a agricultura e a pecuária que fundam o momento crucial da hominização - a revolução do neolítico - a partir de 9.000 a.C. até 3.000 a.C. A partir desse momento, as profundas mutações técnicas, econômicas e sociais marcam a aparição das primeiras cidades.

Ao longo da história ocidental, a carne é considerada uma iguaria, evocando sucesso social e riqueza pessoal daqueles que a consomem. Ela sempre foi a prerrogativa dos poderosos que governam o mundo, senhores, aristocratas e burgueses. A partir da Revolução Industrial, a carne entrou na dinâmica produtivista e consumista do sistema capitalista. Devido a certa democratização, infiltrou-se gradativamente nos regimes alimentares de todas as classes sociais, em especial com o advento da comunicação de massa e da sociedade de consumo. A carne, então, torna-se vulgar, ou seja, comum e disponível a todos. Nesse quadro, a publicidade, que inicialmente ocupa com cartazes os muros das grandes cidades do início do século XX e, depois, é difundida pelas novas "tecnologias de reprodução de imagens" (Benjamin, 1936), faz da carne uma espécie de "alimento totêmico" representativo de uma civilização rica e desenvolvida. Contudo, a carne é um objeto de consumo particular porque contém, em seu seio, uma contradição de ordem semântica. 
Ao mesmo tempo, é uma marca do desenvolvimento social (progresso) e uma testemunha dessa parte animal que nos mantém, o que remete à figura mítica do caçador-coletor.

É necessário compreender que a carne - alimento-totem e marcador social de riqueza - é ao mesmo tempo um símbolo ostensivo do progresso (desde as origens até a modernidade) e um símbolo da parte animal que persiste em nós. Atualmente, essa contradição é objeto de uma clivagem cultural, de um verdadeiro conflito de valores, tanto considerada indispensável ao bem-estar individual e social (progresso) quanto fustigada como a causa de nossos problemas individuais e sociais (animalidade e selvageria).

\section{Linha de desmontagem e ordem industrial}

A Revolução Industrial apoiou-se na lógica da racionalização máxima dos meios e dos processos de produção. As cadeias de montagem representam, de certa maneira, a imagem-tipo, as quais são, na verdade, fundadas não sobre a montagem, mas sobre a desmontagem, em relação às carcaças dos animais. De fato, em seu livro Bidoche, Fabrice Colino (2009) diz que foi observando as cadeias de desmontagem dos matadouros de Chicago que um colaborador próximo a Henri Ford elaborou o caminho inverso para a indústria motora. Nesse sentido, a indústria da carne é um dos porta-estandartes do progresso técnico-científico moderno, acompanhando e sustentando o processo de racionalização de todas as esferas da vida social.

A carne, produzida em cadeia, participa, então, e talvez em primeiro lugar, do que Weber (2002) denominou "desencantamento do mundo". $\mathrm{O}$ abate e o corte dos animais, racionalizados e secularizados, deixam o domínio do sagrado - saída já iniciada pelo dogma cristão, o qual, ao mesmo tempo que fazia de Cristo a figura do último sacrifício, rejeitava definitivamente o sacrifício de animais - para compreender o espírito dos tempos e, portanto, entram no domínio do profano, do cálculo frio e produtivista. Desde então, o constante crescimento da relação produção-consumo de carne resulta de vários fatores, entre os quais o aumento do poder de compra das camadas populares e, simultaneamente, a diminuição do custo de produção da carne.

A zootecnia - ciência integradora que agrupa conhecimentos da genética animal, da etologia, da nutrição, entre outros - torna-se uma espécie de 
locomotiva de toda a produção alimentar moderna. Da mesma forma que outras ciências "progressistas", ela participa, contudo, de um crescimento que excede os parâmetros do racional, o crescimento de um progresso contínuo e sem limite, o único capaz de nos trazer o bem-estar, o qual se institucionaliza como um verdadeiro mito moderno. Enquanto isso, essa crença em um progresso sem freio também pode ser geradora de angústia, inscrevendo-se, então, em uma dinâmica de atração-repulsão que caracteriza, ainda hoje, nossa relação com a indústria alimentar em geral e com a carne em particular (as imagens relativas às diversas "catástrofes" do tipo epizootias são exemplos do lado obscuro dessa força tecnocientífica).

É necessário convir que, à vista da cadência produtivista e consumista das carnes animais, nós nos transformamos progressivamente em "zoófagos". A taxa industrial de abate só tem sentido em função do consumo do objeto em questão. É na devoração e na dilapidação de sua carne que esses animais têm sua razão de ser, e isso sem contar as questões de desperdício alimentar. Não nos parece exagerado sugerir a ideia segundo a qual a cadência que caracteriza doravante o consumo de carne está correlacionada à intensificação do ritmo da vida social, a conhecida "intensificação da vida nervosa", intrinsecamente associada ao surgimento das massas e das metrópoles, segundo Simmel. E o homem - especialmente o das cidades, afastado da natureza - se vê definido (por ele mesmo e de maneira bastante paradoxal) como um megapredador, cuja força e cujo vigor estão correlacionados com sua capacidade de engolir toneladas de carne.

Esse apetite por carne do cidadão moderno é, de fato, paradoxal. Longe de suas origens triviais, desse illud temps no qual ele era um caçador-coletor, o homem das cidades tenta, de certa maneira, preservar essa parte animal em si mesmo ou reanimá-la pelo consumo de derivados de carne. A carne é, então, nesse sentido, uma espécie de vetor simbólico que permite a visibilidade de sua virilidade. Segundo alguns estereótipos grosseiros, o homem verdadeiro, viril e quase bestial é aquele que gosta de comer carne, em grande quantidade e todos os dias. Esse apetite por carne se massificou ao longo do século XX e não mais concerne somente aos cidadãos do gênero masculino, mas ao conjunto das populaçôes ocidentais. Assim, a carne é instaurada não somente como totem do progresso, mas também como elemento de sedução carnal. A atração simbólica pela carne, a ligação mítica associando carne animal e sexual, é, assim, reanimada especialmente pela publicidade. 


\section{O amor pela carne e o espetáculo}

A zoofagia contemporânea é encorajada pela indústria alimentar, que, nos meios publicitários, encontrou um canal privilegiado para difundir uma ideologia "carniceira", "carnívora" ou "carnista" (retomando o termo crítico e militante de Melanie Joy). Isso é evidenciado nos comerciais, que retratam homens, mulheres e crianças exercendo sua verdadeira natureza animal, ou naqueles em que o amor pela carne é explicitamente (não sem humor) associado ao prazer carnal e cuja "moral" reside nas seguintes palavras: "Não tenha medo de dizer 'Eu amo carne'”. Esses processos de marketing poderiam ser rotulados como "propagandistas", como é possível dizer contra qualquer tipo de publicidade, só que a espetacularização da carne ultrapassa a lógica dos negócios.

A obra do artista surrealista Jan Švankmajer, um curta-metragem intitulado Meat love (1989), é particularmente significativa. Ele filma um encontro amoroso, erótico mesmo, de dois filés de carne, no qual eles se dão voltas, em uma dança lasciva, esfregando-se na farinha como em um jogo impertinente e, depois, de maneira rápida e trágica, os dois terminam fritos em uma frigideira. Essa estetização, também encontrada nas obras de Rembrandt ( $O$ boi esfolado, 1655), de Francis Bacon (Figura com carnes, 1955) ou mesmo na produção de Lady Gaga, quando veste o célebre vestido de carne (ainda que ela não seja a primeira, já que a artista Jana Sterback, em 1987, expôs Vanitas - vestido de carne para um albino anoréxico), revela a íntima continuidade entre a carne animal e a sexual, e toda a gravidade tragicômica da existência humana. Um espetáculo que reafirma essa imanência entre o homem e a besta, o homem e sua própria animalidade e o trágico ligando o Eros ao Thanatos.

Por isso, parece-nos necessário discutir, neste artigo, o processo mais geral segundo o qual os produtos da carne se inscrevem, ou seja, o da asseptização dos costumes (Elias, 2003). A instauração sub-reptícia do pudor nas relações sociais e a maneira como isso invade as esferas públicas e íntimas do homem ocidental evidentemente "contaminaram" o domínio alimentar e, particularmente, tudo o que concerne à carne. Seu corte - que anteriormente era operado entre os convidados - é removido, a partir do século XVIII, para outra cena da comensalidade, a cozinha. $\mathrm{O}$ abate e o corte das carcaças também foram depostos das ruas, do coração das cidades, e sua estetização necessária, segundo Noélie Vialles (1987), coincidiria com a mudança da 
sensibilidade, que não quer mais ver a morte nem reconhecer na carne qualquer aspecto relacionado ao animal morto.

A carne, então, paradoxalmente menos animal, transforma-se em puro objeto, sem sangue, limpo e, ao mesmo tempo, testemunha - e participa de - uma reificação geral da vida. Lembremo-nos, no entanto, de sua profunda ambiguidade e do fato de que a carne continua a ser o receptáculo de um tipo de atavismo sem o qual nós não poderíamos compreender que, em uma sociedade pasteurizada, asséptica, o "recurso" à carne seja apreciado como o meio de reencontrar uma espécie de animalidade enterrada. É pelo excesso ou mesmo pelo transbordamento da razão de sua deglutição que ela se torna o meio privilegiado, permitindo reencontrar o primitivo em si mesmo (dieta paleolítica), o homem da floresta, o predador das origens e sua maneira de reintegrar à morte a vida.

No entanto, mesmo esvaziada de todos os atributos primitivos do animal, a carne higienizada permanece o desafio de uma luta de semântica e política. A invasão no corpo social de "novos" valores associados à sensibilidade e à compaixão prejudica os fundamentos simbólicos da alimentação-totem. A reativação dos movimentos vegetarianos no contexto social contemporâneo tem instigado a ideia de que a carne seria um sinal de progresso. Esse vegetarianismo ético que ressurge, de forma mais importante a cada dia, mina a ordem social envelhecida e se apresenta como a panaceia para os males de nossa civilização e de todo o planeta.

\section{A sociedade compassiva}

A partir de 1970, os novos órgãos de defesa da causa dos animais surgem e se munem de uma linguagem relativa à autorreflexão. $\mathrm{Na}$ Inglaterra, a concepção dos direitos dos animais eclodiu em meados do século XIX e ressurgiu nas décadas de 1960-1970, no "Grupo Oxford", consistindo principalmente de filósofos, incluindo Richard D. Ryder, que introduziu o conceito de "especismo". Esse neologismo permite promover a ideia de que a discriminação contra "indivíduos" com base em sua espécie também é injusta e inaceitável, como a discriminação que se baseia em noções de raça ou de gênero.

O fenômeno de libertação animal, assim, não só adquire uma linguagem, mas também uma ideologia racionalista e objetivista que contribui para essa vontade de instaurar um "deve ser" capaz de suplantar "aquilo que é". 
A questão da libertação animal é representada por Henry Salt (1914), um dos principais fundadores da doutrina dos direitos dos animais, sobre essa questão: “Todas as vidas valem ser vividas?”. Trata-se, por exemplo, de denunciar a condição de vida dos gansos forçados à engorda, dos animais voltados às experiências de medicamento e de cosméticos e, em geral, de todos os animais que são criados para morrer. Em outras palavras, portanto, determinar a vida ou a morte, como no caso dos gansos, de animais destinados à experimentação e à alimentação, o que, de modo geral, se passa com todos os animais levados, por fim, à morte.

O fenômeno de libertação animal pode ser apreciado e compreendido como uma brecha no antigo antropocentrismo e também como uma brecha no modelo social ideal moderno, desafiando a ordem simbólica dominante. Mais que um desafio, é uma denúncia de toda a exploração de animais, haja vista a ostentação da indústria da carne. Nessa perspectiva, o progresso, obviamente, não reside no consumo de carne. Ao contrário, a carne é considerada um estigma que vem sujar o dito progresso e os mesmos princípios da humanidade. De acordo com a ideologia dos direitos dos animais, o homem de hoje deve emergir dessa vulgaridade bestial, arrepender-se de todos os horrores infligidos aos animais, nossos "irmãos não humanos". Esse arrependimento começa com a recusa ao consumo de carne.

\section{Ressurgimento da ética do vegetarianismo}

O antiespecismo - que se apresenta como uma crítica racionalista e política - reside na aposta dos fundamentos do direito e, em particular, dos critérios de exigência que introduzem o princípio da igualdade. Destacando que esses critérios não se baseiam em fatos, mas em uma ideia abstrata da unidade humana, a igualdade é entendida como um conceito jurídico, e não como uma simples afirmação de fatos. Com base nos fundamentos morais enunciados por Jeremy Bentham ${ }^{3}$ (de que Salt se fez herdeiro), cada um vale por um e ninguém conta por mais de um; as disposições em questão, apoiadas no comportamento, voltadas para os outros, não devem depender das características e capacidades dos seres em questão. Portanto, se

3 Bentham trabalhou com a filosofia do utilitarismo e com a noção do panóptico na primeira metade do século XIX. 
renegociarmos a igualdade de todos os animais "humanos" e "não humanos", também poderemos renegociar nosso comportamento com eles, até mesmo os mais simples. E, se os animais (do bicho-da-seda ao gado) têm o mesmo valor (legal, moral e político) que nós, os homens, torna-se inconcebível servirem, por exemplo, para fins alimentares, pois isso representa o paroxismo da injustiça.

O animalismo agora cresceu para se tornar um "fato social total", segundo Marcel Mauss, de integração, dentro de todas as estruturas sociais, e o veganismo corresponde a seu advento, guiando os consumidores, "iluminados", a adotarem um modo de vida exemplar. Dentro dele, é necessário distinguir dois tipos de posição: o chamado "reformista" e o mais radical, chamado "abolicionista". Em ambos, podemos notar sua concordância em torno da ideia de "bem-estar", ultrapassando a esfera humana para chegar à dos "seres não humanos". A perspectiva abolicionista do fenômeno nega qualquer continuação, mesmo no curto prazo, à exploração de animais que passem por esse trágico "mal necessário", ou seja, ver a morte de todos os animais que estão sendo mantidos presos, para, no futuro, não nascerem outros animais nessa situação.

Esse ressurgimento contemporâneo do vegetarianismo ético implica para além da alimentação - um modo de vida cujo ideal é fundamentalmente ascético (uma vez que se baseia na recusa, ou seja, na abstinência de qualquer produto ou prática de consumo envolvendo dominação do homem sobre os animais) e que deve ser entendido em relação a um contexto social complexo. As normas e os valores que estruturavam até aqui uma força simbólica tendem a se enfraquecer em contato com uma crise global de significação. Essa crise concerne não somente à alimentação, mas também à política, à justiça e à economia. $\mathrm{O}$ veganismo é como uma tentativa de dar um novo significado, ainda que radical, às nossas relações mantidas com os animais, renegociando os conceitos de justiça e equidade e, em última instância, contaminando os domínios político e econômico. Se a perspectiva abolicionista permanece extrema, os princípios gerais do veganismo começam a se infiltrar no conjunto do corpo social. Aos poucos, a natureza radical desse estilo de vida e visão de mundo penetram as instituições ao mesmo tempo mediáticas e estáticas para se tornar uma modalidade de consumo ainda certamente muito marginal, mas com a pretensão de se estender a todos. 


\section{De um "dia sem carne" a uma sociedade reconhecida como "sem crueldade" ("humana")}

A primeira obra que menciona a possibilidade concreta de não mais se alimentar de quaisquer produtos de origem animal data de 1910, No Animal Food, de Ruppert Wheldon. O termo vegan foi concebido, em 1944, a partir das primeiras e últimas letras do vegetarian, pelos fundadores da Sociedade Vegana, Donald Watson (diretor de The Vegan News) e Elsie Shrigley, os quais se recusaram, por parte da Sociedade Vegetariana, a promover um modo de vida com produtos lácteos. A Vegan Society fornece uma definição: "O veganismo é um estilo de vida que procura excluir, na medida do possível e do realizável, todas as formas de exploração e crueldade contra os animais, quer para a alimentação, vestimenta ou com qualquer outra finalidade", ${ }^{4}$ e indica as características relativas a todos os indivíduos que reivindicam a doutrina:

Um vegan é alguém que tenta viver sem explorar os animais, para o bem-estar dos animais, dos humanos e do planeta. Especificamente, os vegans excluem todos os produtos de origem animal da alimentação (carne, leite, ovos ou mel, entre outros). Eles também evitam vestir-se de couro, lá, seda e quaisquer outros afins".

Ao desconstruir o conjunto de nossas modalidades de existência (trabalho, médico, entretenimento, tradição), o veganismo vai além da preocupação alimentar e revela uma estrutura simbólica e totalizante.

A preocupação essencial dos fundadores do veganismo consistiu em recusar o sofrimento inutilmente infligido aos animais e salientar a dignidade de uma civilização cuja alimentação ainda se baseia no parasitismo cruel dos mais fracos. $\mathrm{O}$ veganismo contemporâneo se sobrepõe a essas consequências nefastas para a saúde do homem e do meio ambiente, provenientes do consumo de produtos de origem animal, denunciando indiscriminadamente as "mentiras da indústria do leite" e dos medicamentos, apontando para os desperdícios e as consequências atrozes de epizootias dos animais ou o desmatamento.

${ }^{4}$ Disponível em: http://www.vegansociety.com/about/who-we-are.aspx.
5 Idem. 
Em suma, o veganismo recorre à vulgarização cientifica ou à pseudociência para sua promoção, como uma alternativa saudável e sustentável. A "literatura" relativa à doutrina do veganismo tenta demonstrar os males do consumo de produtos da indústria agroalimentar considerada responsável por novas doenças (câncer, diabetes, obesidade, depressão). É nessa perspectiva que o veganismo, como doutrina e prática, reivindica um estilo de vida mais saudável, tanto para homens quanto para os animais (liberando finalmente uma tirania ancestral), que só é capaz de salvar o ambiente natural, social e moral com o estabelecimento, aqui e ali, de algum "dia sem carne".

Os vídeos de matadouros filmados por ativistas animalistas, transmitidos nas redes eletrônicas e na televisão, despertam indignação e repulsa em todos. Os bastidores mostram um cenário realmente doloroso e provocam questionamento sobre o sistema industrial de produção-abate. A lógica capitalista e consumista faz com que a cadência econômica não se possa dar ao luxo de cumprir com os regulamentos legais sobre o sofrimento dos animais e sobre quaisquer crueldades intrínsecas aos que trabalham nessas condições. Mas, em vez de contestar a maneira de fazer os arranjos para o abate de animais, os coletivos e militantes animalistas aproveitam essas manifestações para despejar sua ideologia totalitária. Para a pergunta "Como o abate pode ser mais respeitoso com os animais?", os animalistas retrucam: "É possível matar um animal contra a sua natureza de maneira respeitosa?”. É necessário aqui compreender que a negociação não é admissível, já que, na perspectiva animalista do veganismo, matar um animal é assassinato. No entanto, em termos de comunicação, é raro que os ativistas convidados em programas de televisão ou no rádio se permitam usar seu próprio vocabulário. Eles "convertem" ou traduzem suas palavras em outras que sejam compreensíveis a todos. Então, como na metáfora de "cada passo de uma vez", os ativistas sugerem a criação de um dia sem carne; depois, sugerem que pode ser bom estender esse princípio a todos os dias da semana e, que, por exemplo, a carne seja proibida nas cantinas das escolas. Passo a passo, partindo de um "dia sem carne", desliza-se sub-repticiamente ao estilo de vida vegan, com o certificado "livre de crueldade".

\section{Considerações finais}

A alimentação pode ser apreciada como um prisma através do qual avaliamos como os ideais e os valores se cristalizam no corpo social. Trata-se de um 
fato social totalmente revelador das ordens simbólicas em gestação. Nada é mais significativo do que algo considerado comestível e, então, recordamos a frase de Brillat-Savarin: "Nós somos o que comemos". Lugar de todos os tabus (sagrados ou saudáveis) e também de todas as transgressões, a alimentação é a expressão estética por excelência, no sentido de que se desenvolve por meio de nossa relação com o mundo, negociando nosso lugar no ambiente natural e social.

O mito da felicidade moderna estende-se, de certo modo, a nossos "irmãos não humanos", que participam do futuro obsceno de sua morte. Essa morte, ao mesmo tempo considerada injustificada e injustificável, prolonga, por outro lado, a asseptização dos costumes e dos homens, e desenha o esboço de uma sociedade sem sangue. Como destaca Pascal Bruckner em Euphorie perpétuelle (2000), o progresso moral fez do mal e da morte heresias e, de nós, os culpados de cada infração cometida. Em um artigo intitulado Comment les processus de civilisation se sont-ils prolongés?, Cas Wouters (2010) destaca a maneira como a informalização dos costumes e a emancipação das emoções levaram a uma autorregulamentação dos indivíduos de uma "terceira natureza".

Em suma, essa perspectiva pode ser resumida em uma espécie de busca para encontrar a "primeira natureza" (das origens), sem se isentar da "segunda” (como descrito por Elias, já mencionado), o que é acompanhado por uma alteração da ideia de "consciência", em vez de "tomada de consciência". A tomada de consciência de si mesmo, dos outros e do meio ambiente.

Nesse ambiente social contemporâneo, marcado por religiosidades um tanto radicais, por vezes difusas, o bem-estar e o bom tratamento tornaram-se valores não negociáveis, tornando-se ainda mais delicada a ideia de que a carne vem sendo considerada silenciosamente um tabu existencial, estigma de barbárie, do qual o veganismo é o justiceiro. Engajado na luta, principalmente comunicacional (com o uso de imagens-choque, tais como a de $P_{e t a^{6}} \mathrm{em}$ uma campanha contra a KFC exibindo uma "galinha crucificada"), contra os sanguinários de uma sociedade domesticada, o animalismo enterrou ainda mais profundamente essa parte animal, em que alguns, muitas vezes pelo excesso (na imagem de todos os competitivelspeed eaters em todo o mundo), tentam revelar sua superioridade.

Assim, o espírito dos tempos é marcado não só pelo que Weber (2002) chamou de "politeísmo dos valores", mas também por um verdadeiro com-

${ }^{6}$ People for the Ethical Treatment of Animals. 
bate, em que, de um lado, vemos se afrontarem os deuses do sangue e da carne e, de outro, os deuses da compaixão e do ascetismo benevolente. A modernidade envelhecida e deliquescente é o momento em que o "paradoxo das consequências”, dos quais Weber (2002) falava, torna-se uma espécie de efeito perverso resultante de uma inversão de valores que já foram estruturantes da ordenação social e que não fazem mais sentido - em todo caso, não mais para todos. Então, os críticos desta época que se encerra participam do devir de uma sociedade sem sangue, em que o futuro da carne reside nesse oxímoro conceitual: o bife in vitro.

\section{Referências}

BARATAY, Eric. Le point de vue animal: une autre vision de l'histoire. Paris: Éds., 2012.

BARTHES, Roland. Mythologies. Paris: Seuil, 2010.

BENJAMIN, Walter. L'ouvre d'art à l'époque de sa reproductibilité technique. Paris: Payot, 1936. BRUCKNER, Pascal. L'euphorie perpétuelle: essai sur le devoir du bonheur. Paris: Éds. Le Livre de Poche, 2000.

CELKA, Marianne. "L'animalisme. Enquête sociologique sur une idéologie et une pratique contemporaines des relations homme/animal”. S.l., 2012. Disponível em: http://www. theses.fr/2012MON30040.

DURAND, Gilbert. Les structures anthropologiques de l'imaginaire. Paris. Dunod, 1993.

ELIADE, Mircea. Le mythe de l'éternel retour. Paris: Folio Essais, 2001.

ELIAS, Norbert. La civilisation des mours. Paris: Éds Calmann-Lévy, 2003.

—. La dynamique de l'Occident. Paris: Éds Calmann-Lévy, 2011.

LESTEL, Dominique. Apologie du carnivore. Paris: Fayard, 2011.

LIOGIER, Raphaël. Souci de soi, conscience du monde. Vers une religion globale? Paris: Armand Colin, 2012.

MAFFESOLI, Michel. “Tribalisme postmoderne”. Sociétés, Paris: De Boeck Éditions, v. 2, n. 112, 2011.

MORIN, Edgar. L'esprit du temps. Paris: Grasset, 1962.

NICOLINO, Fabrice. Bidoche, l'industrie de la viande menace le monde. Paris: Éds. Les Liens qui Libèrent, 2009.

TOFFLER, Alvin. La troisième vague. Paris: Éds. Denoël, 1984.

VIALLES, Noëlle. Le sang et la chair: les abattoirs des pays de l'Adour. Paris: Éds. de la Maison des Sciences de l'homme, 1987.

WEBER, Max. Le savant et le politique. Paris: 10/18, 2002.

WOUTERS, Cas. "Comment les processus de civilisation se sont-ils prolongés? De la seconde nature à la troisième nature”. Vintgième siècle, v. 106, n. 2, 2010, pp. 161-75. 